
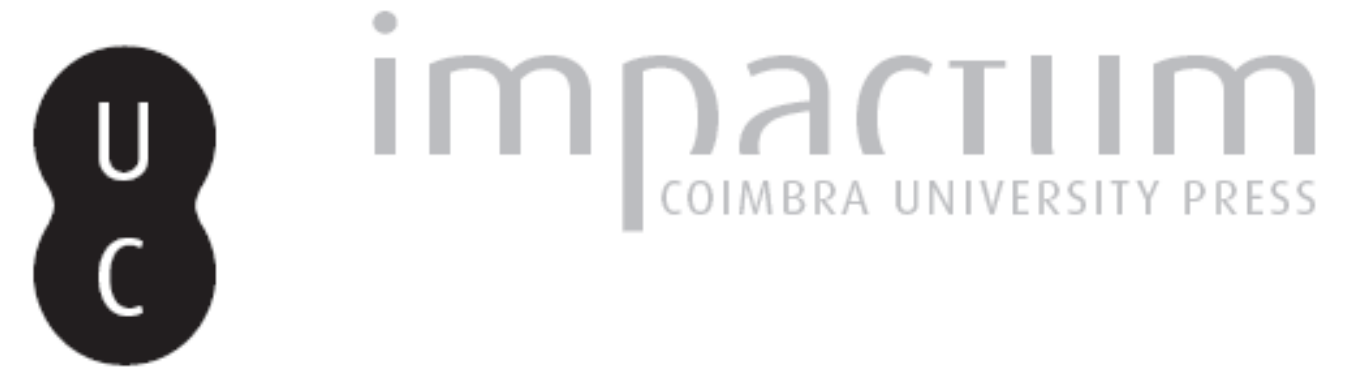
Note sur l'occupation française des provinces basques au temps des guerres de la
Convention (1794-1795)

Autor(es): $\quad$ Domergue, Lucienne

Publicado por: Imprensa da Universidade de Coimbra

URL persistente:

URI:http://hdl.handle.net/10316.2/43763

DOI:

DOI:https://doi.org/10.14195/2183-8925_10_4

Accessed : $\quad$ 26-Apr-2023 16:30:44

A navegação consulta e descarregamento dos títulos inseridos nas Bibliotecas Digitais UC Digitalis, UC Pombalina e UC Impactum, pressupõem a aceitação plena e sem reservas dos Termos e Condições de Uso destas Bibliotecas Digitais, disponíveis em https://digitalis.uc.pt/pt-pt/termos.

Conforme exposto nos referidos Termos e Condições de Uso, o descarregamento de títulos de acesso restrito requer uma licença válida de autorização devendo o utilizador aceder ao(s) documento(s) a partir de um endereço de IP da instituição detentora da supramencionada licença.

Ao utilizador é apenas permitido o descarregamento para uso pessoal, pelo que o emprego do(s) título(s) descarregado(s) para outro fim, designadamente comercial, carece de autorização do respetivo autor ou editor da obra.

Na medida em que todas as obras da UC Digitalis se encontram protegidas pelo Código do Direito de Autor e Direitos Conexos e demais legislação aplicável, toda a cópia, parcial ou total, deste documento, nos casos em que é legalmente admitida, deverá conter ou fazer-se acompanhar por este aviso.

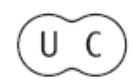


REVISTA DE HISTORIA DAS IDEIAS IO
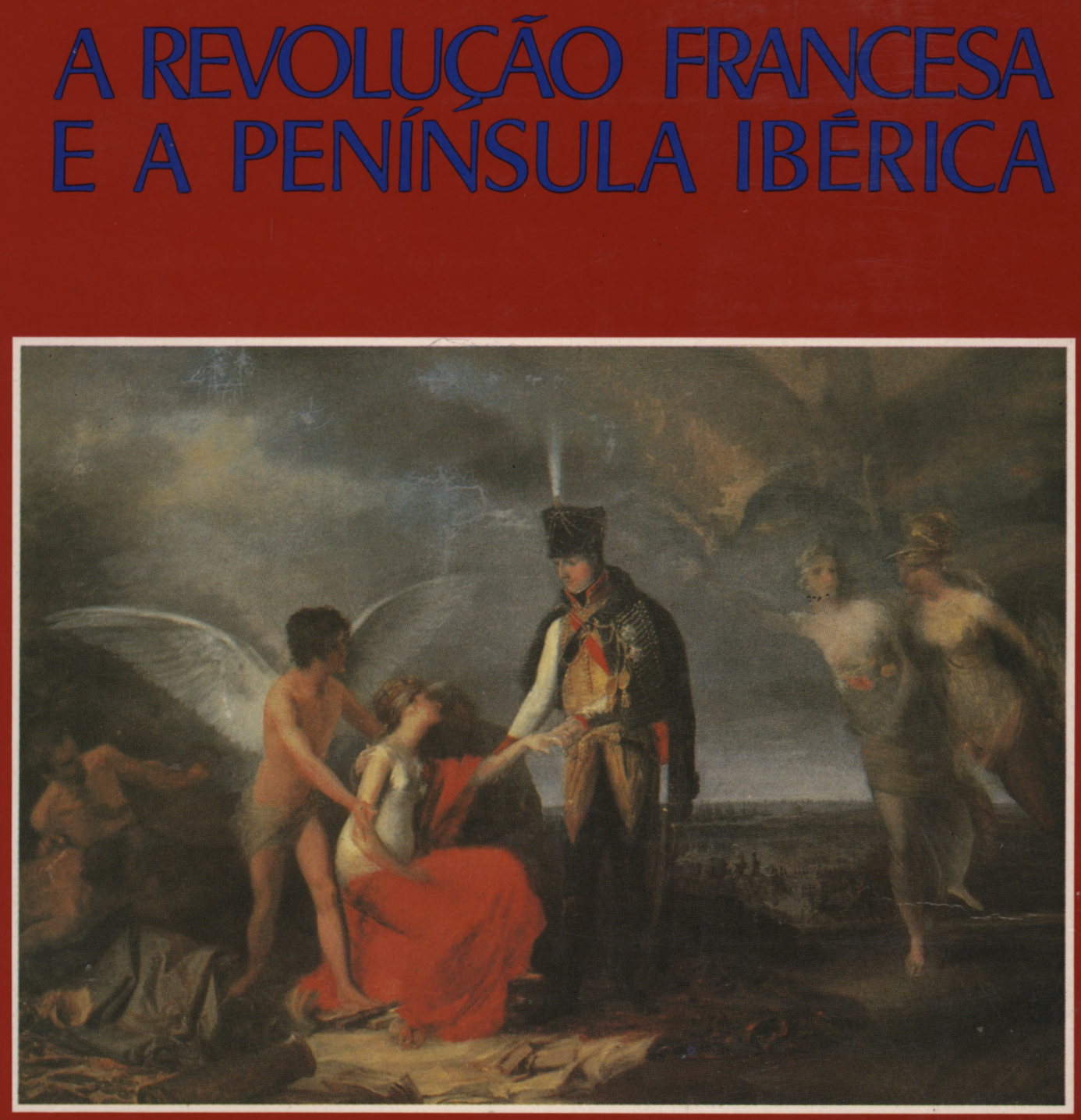

INSTITUTO DE HISTÖRIA E TEORIA DAS IDEIAS FACULDADE DE LETRAS 


\section{NOTE SUR L'OCCUPATION FRANÇAISE DES PROVINCES BASQUES AU TEMPS DES GUERRES DE LA CONVENTION (1794-1795)}

\section{Occupation et «collaboration» au sud de la Bidassoa}

La guerre contre la Convention avait, pour l'Espagne, débuté sous les meilleurs auspices. Indignés par la décapitation d'un roi, chauffés à blanc par l'éloquence de leur clergé, les sujets de Charles IV s'étaient lancés dans la bataille à corps perdu avec une générosité et une fougue que le gouvernement se plaisait à souligner. De fait, des victoires à l'ouest et surtout à l'est des Pyrénées leur permettent de franchir la frontière au cours de la campagne de 1793; mais l'enthousiasme sera de courte durée et, dès l'année suivante, la fortune change de camp, à un bout de la cordillère comme à l'autre. Le 3 juin 1794 la bataille de Berdaritz ouvre le pays aux Français. Une déception immense s'empare du peuple basque qui, en dépit de ses fueros, avait, au cours de la campagne précédente, payé de ses fcrces vives, en levant des bataillons de volontaires, pour ne rien dire de ses deniers. Les troupes espagnoles ont fait preuve de leur inefficacité et beaucoup ne sont pas loin de juger, que la monarchie les a abandonnés. C'est dans ce contexte qu'eut lieu ce que l'historiographie espagnole a appelé la «séparation» du Guipuzcoa; dans les premiers jours d'août, les armées de la Convention donc forcent la frontière; les places d'Irun, Vera, Fontarrabie tombent; l'alcalde Michelena ouvre les portes de Saint-Sébastien; le gouvernement de la Province, à savoir la Junta de Guetaria, avec des leaders tels que, entre autres, José Fernando Echave y Romero, diputado general, et Joaquin Barroeta y Aldamar, traite de puissance à puissance avec la

* Université de Toulouse-Le Mirail. 
République française. Cette attitude collaborationniste semblait partagée à cette date par une bonne partie de l'opinion basque, qui jugeait de façon sévère la politique madrilène. Il n'est jusqu'à un aumonier militaire, Vicente de Eriba $\left(^{1}\right)$ qui, après la prise d'Irun, manifeste sa sympathie pour le gouvernement français: peu importe, dit-il, l'entrée des conventionnels en Espagne, du moment qu'ils laissent la religion libre et qu'ils respectent les personnes et les biens, puisque c'est en cela que consiste le bonheur. Il ajoutait que la Province avait très bien fait de se rendre, vu la conduite de «nos» troupes et vu le désintérêt qu'avait manifesté le Cabinet en n'envoyant aucune aide. Le prêtre en question tenait bien imprudemment ces propos à Calahorra où il s'était réfugié; on s'empare de lui, on le jette dans la prison royale, puis il est expédié dans un couvent d'où il prétend s'expliquer; mais Godoy fait la sourde oreille sous prétexte qu'«il ne convient pas pour l'heure d'en user trop souvent avec indulgence».

Miguel de Mendinueta, un membre connu du Conseil de Castille, est l'un des premiers envoyés spéciaux dépêchés alors par Madrid dans les provinces basques $\left(^{2}\right)$. Ce représentant en mission hispanico more semble n'être arrivé en Guipuzcoa qu'en août 1794; or Saint-Sébastien tombe dès le 4. Juriste habile, il s'est vu confier la tâche d'empêcher l'application des fueros «dans les circonstances présentes», c'est-à-dire d'arracher la Province à son quant-à-soit et l'inciter à jouer à fond la carte espagnole. De plus Mendinueta va s'employer à expédier à Madrid toute l'information qu'il va bientôt rassembler par l'intermédiaire des Espagnols vivant en territoire récemment occupé; ainsi le $1 .^{\text {er }}$ janvier 1795 il fait parvenir copie de documents émanant des troupes d'occupation: il s'agit de fêter sous peu l'exécution de Louis XVI survenue deux ans plus tôt. A côté d'une affiche signée Baudot, représentant du peuple à Bayonne, 29 nivôse An III: "La mort des rois, c'est le salut des peuples», où il est fait état du décret de la Convention du 21 nivôse prescrivant la commémoration de la fin du roi, on trouve, en date du 30 nivôse, un extrait du compte rendu par le général de l'armée française, de la fête célébrée le 2 pluviôse, à deux heures, et destinée à rappeler, par deux salves d'artillerie, le jour «où tomba la tête de Capet, et dédier sa mémoire à l'exécration de la postérité républicaine». De cette célébration d'un genre nouveau, qui jusqu'en 1795 n'avait pas figuré, on s'en doute, dans les éphémérides de la Province,

(1) Archivo Historico Nacional, Estado 3153-13.

(2) A.H.N. Estado 40402. 
nous trouvons témoignage dans la plainte $\left(^{3}\right)$ présentée un an plus tard devant les autorités de la ville de Tolosa contre six habitants - certains étant d'origine française -, qui, pour donner encore plus de gages à l'occupant, ont participé activement à ces manifestations:

"No satisfechos aún de tantos servicios y de tan infames maniobras, para llenar la medida de los delitos y convencer a los Republicanos de sus sentimientos y de su aborrecimiento a los Reyes, asistieron al horrendo aniversario de la muerte del desgraciado Luis XVI que se celebró el 23 de enero en la plaza de esta villa, alrededor de su infernal árbol de la libertad; allí cuando el poco vecindario que quedó gemía dolorosamente al ver ultrajado a su Rey y Señor natural, cuando los buenos Guipuzcoanos tenían su corazón traspasado de pena al presenciar semejantes desacatos, los Carreses, Aguirre, Urrutia, Zubiburu y Danglada (ce sont, bien entendu, les "collaborateurs" incriminés) ostentaban la más gustosa satisfacción, danzaban con los Franceses entre festivas canciones alrededor del árbol, y después de haber practicado las ceremonias de su inmundo ritual a vista de un pueblo entero, prorrumpieron en aquellas pérfidas acciones de deslealtad y de traición que reproducían la trágica muerte de Luis XVI, los deseos de conservar la República y de matar a nuestro amabilísimo Monarca; se acercaban al árbol. le besaban. miraban hacia Francia y exclamaban: ¡Viva la República! Volvían a besar, cerraban el puño y convirtiéndose hacia Madrid, se mantenían un rato en la más fiera postura, significando en mudo pero horroroso lenguaje que estaban dispuestos a ejecutar en nuestro adorado monarca la misma vileza y atrevido desacato que en el suyo. Cometido este crimen, ia aué no se abalanzaría su desenfrenado esníritu? ¿Oué linaie de delito sería ajeno de sus almas traidoras y desleales?»

Cette fête. qui peut sembler cruelle et haineuse puisqu'aussi bien elle célèbre dans l'allégresse non pas un avènement, une naissance, ici celle de la République, mais la décapitation d'un roi déià destitué. se déroule en pays conquis exactement comme si l'on était dans la France révolutionnaire: les inévitables danses endiablées et joyeuses chansons autour de l'arbre de la liberté qualifiées ici de «rituel immonde» semblent une entrée en matière, une mise en forme avant de procéder à l'évocation de l'événement qui les occupe précisément ce jour-là: la décapitation du roi. On nous dit de ces

(3) A.H.N., Estado 3161-1; ce document est signalé par P. Fernández Albadalejo, La crisis del Antiguo Régimen en Guipúzcoa (1766-1833), Madrid, Akal, 1975. 
citoyens que, tels des acteurs, ils miment ensuite les «perfides actions» qui reproduisent la fin tragique de Louis XVI, et l'on peut penser qu'ils ont reçu pour cela des consignes de France où la fête a dû se dérouler de la même manière. Cependant le dernier acte semble avoir été, à Tolosa, improvisé, ou à tout le moins adapté à la situation exceptionnelle d'une cité placée naguère sous l'autorité de Madrid; d'où le cérémonial décrit par le menu dans la plainte citée plus haut et qui est peut-être né spontanément; cet art des gestes et des attitudes, que les révolutionnaires ont hérité, comme bien d'autres pratiques de la Rome antique, cette pantomime délivre un message, parfaitement explicite, encore que sans paroles, de haine contre la monarchie espagnole.

La colonie française - ou d'origine française - de Tolosa n'avait pas attendu le mois de janvier 1795 pour trahir ses vrais sentiments. La Querella que nous avons sous les yeux et qui est datée de février 1796, nous fait remonter aux premiers temps de la pénétration des troupes de la Convention sur le sol guipuzcoan:

«....Rotas nuestras líneas de Irún por los Franceses el 1.o de agosto del año pasado de 94, se acercaron éstos los siguientes días a Hernani, en donde asentaron su cuartel por entonces para arreglar desde allí las sucesivas operaciones contra nuestro ejército y Provincia invadida. En este punto recibieron aviso de Don Pablo Carrese, como primera prenda de su afición, para que sin perder momento viniesen a esta villa y se apoderasen de sus alturas antes de reforzarse los Españoles, cuya noticia y luces debieron influir seguramente en el ataque que se realizó contra nuestras tropas en 9 del mismo mes, logrando con él desalojarlas de esta villa y sus inmediaciones con notable pérdida de las mismas, y abriendo las entrañas del país al enemigo. Dueños ya de este pueblo, descubrieron de lleno los que van dichos la deslealtad, irreligión y espíritu republicano que los animaba, pues no puede escogitarse diligencias, medios ni trazas de que no se aprovechasen para fomentar a sus paisanos en todas sus empresas y necesidades.

A su entrada los Carreses, arrastrados de esta traidora inclinación, recibieron a nuestros enemigos con la más extraordinaria complacencia, les franquearon su casa con demonstraciones de la mayor inclinación y alegría, y comenzaron desde luego a ponderar la humanidad y disposiciones de la República. Ya escribían a sus conocidos que no se moviesen de sus casas, ya intimidaban a los infelices. paisanos para tenerlos quietos y desarmados, y ya daban a entender con sus abultadas relaciones el poder de los enemigos, su dureza con los que se resistían o tomaban las armas. Los Carreses, Aguirre, Urrutia y Zubiburu acompañaron a los Franceses en la invasión que hicieron en la villa 


\section{L'Occupation Française des Provinces Basques}

de Vergara en 29 de noviembre, y Don Pablo, de vuelta a su casa, les prometió en Villafranca a su hijo por alcalde, asegurándoles que serían bien gobernados, y luego, cuando llegó a esta villa de Tolosa, sin apearse en su casa ni detenerse con persona alguna, corrió hacia las de Vidiviela y Yurreamendi en el camino de Navarra; lleno de gozo, comenzó a gritar a varias gentes que iban por aquel camino y les dijo que se animasen, que los Franceses habían invadido a Vergara apoderándose de varias riquezas, que también habían entrado en Vitoria y que todo estaba ya franco hasta Madrid; acompañó a los enemigos aún en la invasión de Vitoria, y su estudio único era despreciar abiertamente los sagrados respetos del vassalaje; unas veces decía que los Españoles jamás recobrarían la Provincia ni esta villa, y que primero se convertirían en oro las piedras de sus calles que volviesen al dominio de nuestro Rey; otras desacreditaba los vales reales ponderando en tono de admiración y seguridad los despreciables asignates de Francia; ya enfin servía a sus generales con espías, comunicándoles todos los movimientos de nuestras tropas; su yerno Adrián de Aguirre volvió a serlo casándose en segundas nupcias con la hermana de su primera mujer, e hija del contemporizante e irreligioso Carrese, sujetándose en esta impía determinación a las desenfrenadas leyes de la República. Carrese y su hijo Don José María fueron fieles servidores de ella, procurando por maneras exquisitas sus ventajas, la propagación de sus opiniones y el vilipendio de nuestras costumbres. Ellos salían en compañía del malvado Urrutia $\mathrm{v}$ Republicanos a cuantas incursiones intentaban, y tomaban el más grande interés en sus felicidades, en tanto gardo que sus semblantes tristes y macilentos eran el más seguro presagio de las pérdidas de los Franceses, y por el contrario su alegría y briosos ademanes.

Adrián de Aguirre y Urrutia obligaron a los sacristanes a que pusiesen en público la plata de la Iglesia que estaba escondida, y cayó en poder de los enemigos; los dos rompieron osadamente la pyerta del archivo, en que se custodiaba la plata de Irún y Oyarzun, que igualmente cayó en sus manos. Ellos hicieron pedazos el sagrario de esta iglesia parroquial, se echaron de menos las formas que se acostumbra tener en ellos, y dieron a entender en todo su irreligiosa conducta y libertinaje. En casa de Aguirre a la vista de un comisario francés y Urrutia, José María Carrese azotó a un Cristo sin algún remordimiento, y pretendieron bautizar a un gato para ridiculizar nuestros más respetables sacramentos, para descubrir el desprecio que se merecian nuestras leyes políticas y religiosas, y para hacer ver a los Franceses que sus costumbres no desdecían un ápice de las que ellos traían, y en fin que, aunque habían nacido en su suelo piadoso y lleno de respeto, sabían vivir a la francesa. Fueron municipales con Don Pablo, Urrutia y Danglada; se llevaban toda la atención y confianza de los Franceses; se pusieron la banda y cucarda nacional como testimonio de su adhesión a la República, y blasonaban de adornarse con las insignias de ella. 
El cirujano Zubiburu se presentaba los más de los días muy temprano ostentando los mayores deseos de servir a la República, acompañarles en los ataques a sus soldados, como lo ejecutó varias veces, y se distinguía en usar con los pobres paisanos el más imperioso lenguaje.

Los más de estos se retiraron de esta villa con sus muebles porque la tropa francesa la desamparó, opinando que no era posible conservar este puesto. Pero luego que aquélla volvió por las órdenes de sus comandantes, se restituyeron también ellos a sus casas como inseparables compañeros y amigos de los Republicanos. Con ellos vivían en la más agradable armonía, exageraban desmedidamente sus victorias y pronosticaban al país la suerte más lisonjera en el poderío de los Franceses».

Si nous n'avons pas hésité à citer in extenso un long texte, c'est que nous croyons y découvrir tous les éléments caractéristiques de cette occupation et peut-être d'autres. Il rend compte des hésitations de la conquête française; d'amblée les généraux révolutionnaires, comme leurs homologues espagnols, se montrent timides aux deux bouts de la chaîne pyrénéenne; au terme d'une promenade militaire, Ricardós tient une bonne partie du Roussillon, mais il n'entre pas à Perpignan; au Pays Basque, les attaques à peine déclenchées, s'arrêtent d'elles-mêmes; aussi les deux armées campent-elles sur leurs positions à peu près autour de la ligne frontière pendant plus d'un an, justement jusqu'à l'entrée des Conventionnels à Irún le $1 .^{\text {or }}$ août 1794. Entrée encore timorée, car, s'il faut en croire le témoignage, ils n'ont poussé vers l'intérieur que sur renseignement de Carrese l'Ancien. De plus, leur occupation de Tolosa n'est pas définitive, car ils estiment bientôt qu'ils ne peuvent pas tenir et se replient, emmenant dans leurs fourgons l'équipe des individus compromis. Ces derniers reviennent de la même manière lorsque les Français se ravisent et réoccupent. S'ils ne prennent à aucun moment, semble-t-il, les armes contre l'Espagne, Carrese et ses amis ne plaignent pas leur peine, ils accueillent des troupes et se font leur mentor dans ce pays qu'ils connaissent bien: ils les accompagneront dans toutes leurs sorties et incursions (Vergara, Vitoria); de plus ils se livrent à une double tâche: d'information, comme on vient de le voir, à l'égard des armées d'occupation, et de propagande en direction de la population basque. Cette propagande revêt diverses formes selon les moments et les interlocuteurs; elle n'hésite pas à aller jusqu'à l'exagération et l'intoxication, le mensonge caractérisé, quand par exemple à la fin de novembre 1794, les Français, poussant vers l'ouest, s'emparent de Vergara; Carrese, qui les a escortés, rebrousse aussitôt chemin pour parcourir le pays et se faire leur héraut; ce qu'il 
semble avoir en tête, c'est de préparer les esprits afin que les villes ouvrent, sans coup férir, leurs portes aux «libérateurs». Ainsi il est de passage à Villafranca de Oria où il offre son fils pour gouverner la ville, puis, dépassant Tolosa et courant vers l'est, le voilà qui raconte ce qui vient d'arriver à Vergara, mais il lui faut grossir les choses: les Français, assuret-il, sont à Vitoria, et s'il n'ose pas affirmer qu'ils sont déjà à Madrid, c'est comme si c'était fait: la voie est libre.

Les zélés progandistes de son espèce utilisent tour à tour la promesse et la menace: le populaire n'a pas droit à de grands égards, de la part de ces partisans de la Révolution, qui en fait, on s'en douterait, sont des bourgeois: au tout-venant (infelices paisanos, pobres paisanos) ils font peur afin qu'il ne bronche pas, tandis qu'à leurs amis et connaissances que, pensant enrayer l'hémorragie de la population qui a vidé Saint-Sébastien de la moitié de ses habitants, ils exhortent à rester bien tranquilles chez eux, ils louent les procédés des républicains dont ils vantent l'«humanité», usant d'un mot qui fera fortune dans la péninsule à la fin de ce siècle; tout ce qui vient de ces héros invincibles est bon et avantageux: leurs assignats sont admirables et sûrs; sous la houlette des Conventionnels, le pays nagera dans la félicité.

A côté de la propagande active la collaboration comprend la participation aux nouvelles institutions politiques mises en place par l'envahisseur: on a vu le fils Carrese s'offrir à gérer les affaires de Villafranca, et à Tolosa même le père est conseiller municipal avec Urrutia et Danglada; tous ces gens arborent donc la cocarde et l'écharpe tricolores, ce qui eût suffi à ne pas les faire passer inaperçus; chacun y va de sa spécialité: Zubiburu n'est qu'un vulgaire chirurgien, profession fort peu cotée dans l'Espagne d'Ancien Régime, mais fort utile sur les champs de bataille; son zèle est touchant; tel les ouvriers agricoles du Mezzogiorno ou d'Andalousie, il se présente à l'aube et presque chaque jour que le Bon Dieu fait pour se mettre à la disposition des occupants et les accompagner dans leurs sorties militaires, ce que faisaient également volontiers ses compères.

Cependant ce qui était bien pour choquer les braves gens, c'est l'attitude provocatoire de ces individus par rapport à la royauté et à la religion; pour ce qui est du premier point, le récit de la commémoration de la mort de Louis XVI est suffisamment éloquent; en matière d'impiété, le délateur n'est pas avare de détails; ces débordements à eux seuls expliqueraient que, même si depuis 1789 elle ne s'embarrassait plus de scrupules pour poursuivre les ennemis du Trône, l'Inquisition 
ne pouvait marquer pas d'intenter un procès après la paix de Bâle à tous ces afrancesados. Aguirre et Urrutia souhaitent renflouer le trésor de la Convention au dépens de l'Eglise espagnole: ils forcent les sacristains tolosans à exhumer l'argenterie de leur paroisse ainsi que celle d'Irún et d'Oyarzun qu'on avait crû mettre à l'abri; leurs profanations sont parfois gratuites comme lorsqu'ils ont brisé le tabernacle pour subtiliser les saintes espèces; les sacrements leurs inspirent le plus grand mépris: Aguirre, le gendre de Carrese, adopte si bien les pratiques révolutionnaires qu'il laisse sa femme pour se marier en secondes noces avec la soeur de cette dernière; il tient chez lui tertulia (le commissaire français est un assidu), où son beau-frère José Maria a frappé un crucifix (crime que le Saint-Office déjà prêtait traditionnellement à ses victimes, notamment aux judaïsants) et baptisé... un chat.

Mendinueta, qui tient le gouvernement informé de ce qui advient dans le territoire occupé, transmet, au printemps 1795 , une affiche bilingue datée de mars et signée de Moncey. Le général en chef de l'Armée des Pyrénées Occidentales s'y adresse «aux habitants du pays conquis» pour leur annoncer qu'il va installer des officiers de police particuliers et supérieurs pour surveiller les familles espagnoles, car des vols et des assassinats on été commis «sur plusieurs de nos frères». L'atmosphère dans le pays basque occupé n'était pas sans rappeler ce que sera la vie quotidienne en Espagne au temps de la guerre d'Indépendance. Pour une poignée d'afrancesados qui font preuve d'un réel activisme (ainsi ceux que nous avons abondamment évoqués), que de civils faussement résignés qui opèrent de façon clandestine et prennent parfois des habitudes de hors-la loi!

Cependant, avec le début de l'été l'offensive reprend, victorieuse; le 29 juin les Espagnols reculent tant et si bien qu'il ne leur reste plus en Guipuzcoa que 6 pueblos, et Mendinueta ne se fait pas faute de récriminer contre le général espagnol. Le 7 juillet, devant l'avance irrésistible des soldats français, Mendinueta et la Diputación poussent jusqu'à Miranda del Ebro, et de là à Briviesca.

Le Cabinet de Madrid avait envoyé un conseiller de Castille en Alava: Pedro Flores Manzano arrive à Vitoria le 25 novembre 1794. Les choses commencent bien, car dans son rapport daté du $1 .^{\text {er }}$ décembre, il se montre satisfait de ce qu'il voit:

"Se ha hecho una solemne devota rogativa en la Iglesia colegial con asistencia de su cabildo eclesiástico, comuni- 
dades religiosas y cofradías por las calles públicas y acostumbradas».

Le peuple y assiste et participe, sous la houlette de ses pasteurs habituels et légitimes, à un spectacle édifiant et, bien entendu, celui qui a présidé la cérémonie, c'est le légat de Madrid qui note:

«He tenido singular complacencia al advertir la religiosa piedad de estos naturales, el respeto y la sumisión a las majestades y los clamores de tantos sacerdotes y familias desnaturalizadas de Guipúzcoa por la invasión de los enemigos».

Ces derniers ont déjà prouvé que, par fidélité, ils étaient capables d'abandonner leurs biens, leur clocher, et préférer l'exode à l'occupation étrangère. Tous semblent, selon Flores, prêts à sacrifier leur vie "pour la religion, le roi et la patrie»; si les deux premiers termes sont limpides et constamment répétés au XVIIIème siècle, il en va différemment du dernier, qui reste ambigu. La patrie? quest-ce à dire? La monarchie espagnole? Sans doute non, puisqu'on a déjà mentionné le roi. Est-ce la patrie basque? Peut-être seulement s'agit-il de la petite patrie, la vallée, le village, le hameau où l'on a vu le jour.

$\mathrm{Au}$ cours de l'hiver Flores envoie également à Godoy tout ce qui tombe sous sa main en fait de propagande française; c'est que les troupes révolutionnaires de leur côté ne se font pas faute de répandre à l'intention des populations une multitude de textes séducteurs. L'envoyé de Madrid observe:

\begin{abstract}
«Por hallarse la tropa alavesa en los puestos más avanzados del Monte de Elosua, Descarga y Villareal, ha recogido su comandante los papeles adjuntos, esparcidos cuidadosamente en las líneas de los enemigos. Todos los días experimentamos iguales insultos y otros tan denigrativos, particularmente lo que contiene el Monitor que va notado con el número 14 y con rúbrica mía».
\end{abstract}

Le 22 mai 1795 Luis Antonio Candamo, ci-devant administrateur des postes à Bilbao, à présent replié à Vitoria, se fait à son tour l'informateur zélé du ministère $\left(^{4}\right)$ auquel il communique régulièrement ses prises; outre le journal - manuscrit des opérations des troupes espagnoles régulières - désigné sous le nom de Diarios de Mondragón y Villareal -, il adresse des imprimés français, traduits en castillan par l'ex-jésuite Marti-

(4) A.H.N. Estado 2906. 
nez, natif de Logroño et interprète à Bayonne de l'Etat-Major de l'armée révolutionnaire; il les tient de José Joaquín de Amestoy, responsable des postes à Vergara, qui l'a averti que depuis quelques jours arrivent de Saint-Sébastien des femmes porteuses d'imprimés séditieux adressés à divers individus de cette ville, émigrés ou non. Le 26 mai, Godoy accuse réception en ordonnant de saisir tous ces documents et de chercher à cornnaître qui dans ce pays correspond avec les «séducteurs».

Dès lors on intercepte fréquemment les journaux qui ont été glissés dans le courrier personnel; on y trouve en particulier le Moniteur n..$^{\circ} 243$, daté du 3 prairial (22 mai 1795) qui renferme le rapport de Moncey sur l'armée des Pyrénées Occidentales. Le 9 juin Candamo a pu récupérer pour Godoy un compte rendu de la séance de la Junte générale des autorités constituées et des habitants tenue à Saint-Sébastien le 21 floréal (10 mai), ainsi que des proclamations, en castillan et en français: l'une d'elles (bilingue et sur deux colonnes), datée de Saint-Sébastien le 27 germinal et signée du représentant en mission Chaudron Rousseau, reprend pour l'essentiel le long rapport de 11 pages lu le 27 germinal par Tallien devant la Convention au nom du Comité de Salut Public $\left(^{5}\right)$ et dont on

(5) Le rapport de Tallien, très sensibilisé à l'Espagne ou du moins au Pays Basque (par l'entremise des Cabarrus, un clan commercial franco-espagnol et basque, dont il pouvait avoir épousé la cause en convolant avec un beau fleuron de la famille qu'il avait sauvé de la guillotine: Teresa Cabarrus dite Notre-Dame de Thermidor), marque un virage dans la politique de la Convention après la chute des montagnards, que Tallien, lui-même montagnard repenti, accable de tous les maux et charge de toute la responsabilité dans les brutalités que la République a prodiguées envers le Guipúzcoa. Le texte montre qu'à Paris on veut faire oublier ces violences:

«....La Provincia de Guipúzcoa, ocupada por el ejército de los Pirineos Occidentales, y la de Bizcaya, que es contigua, son dignas de un gran interés por sus producciones y no menos por el carácter de sus habitantes. En medio de la servidumbre general han conservado mucha parte de libertad. Muchas de sus leyes constitucionales tienen gran conexión con las nuestras. Éstas son una fuerte barrera que el espíritu y la razón de los pueblos han formado entre el despotismo y sus derechos. Juzgaréis el espíritu general de estas leyes por el tenor de la ley 2" que se explica así: 'Si un enviado del poder arbitrario se presentara en la Provincia de Guipúzcoa, el primer ciudadano que lo encontrare, debe mandarle que se retire; si lo rehusa, debe volverselo a mandar, y a la 3a matarlo'. El carácter de los habitantes de aquellos países es enérgico como sus leyes: nacido para la libertad y naturalmente penetrado de amor y afecto para con los pueblos que combaten por ella, es entre todos aquellos en cuyo territorio han entrado las armas de la República el que las ha visto acercarse con menos espanto.

Vuestra Junta guardará el silencio sobre el detalle de los horrores cometidos en estos países por los ordenadores en jefe y por los ejecutores subalternos; se contendrá por razones que penetrará su 
avait tiré des affiches en espagnol; il existe également une affiche bilingue sur deux colonnes, d'un contenu comparable, intitulée: Proclamación de la Junta de Salud Pública de la Convención Nacional de Francia a los habitantes de la Provincia de Guipúzcoa et datée de ce même 27 germinal. Un grande affiche bilingue, sur papier gris signée de Saint-Sébastien le 28 germinal, constitue une mise en demeure aux populations du pays: «Que todos los habitantes del país conquistado, sean de los pueblos, sean de las caserías, que se han retirado por

sabiduría y se ceñirá a algunos hechos. En Cataluña a la entrada de nuestros ejércitos, las ciuaades, lugares y barrios estaban desiertos; el pueblo huia, cargado de cuanto poaia de muebles y efectos, y quemaba 1o que te era imposible llevar, consiguiendo de esto modo su odio y su terror no dejar a nuestras falanges victoriosas sino un país falto de subsistencias y habitantes.

El pueblo de Guipúzcoa se mantenía a nuestra entrada, pacífico en sus hogares, o se nos presentaba contento de una conquista que le prometía la restitución de sus derechos y muy distante de pensar de un pueblo generoso y libre lo que las naciones más esclavas y feroces no rehusan a los pueblos que conquistan, esto es la ejecución precisa de las condiciones bajo las cuales se someten; pero el sistema sanguinario, loco y destructivo que en aquella época oprimía a la Francia debía extenderse sobre sus conquistas. Veréis aquí el detalle de algunos excesos y crímenes que se han cometido; nos es sensible el no poderlos ocultar a vuestra penetración. La ciudad de San Sebastián abrió sus puertas sin resistencia; los lugares de Guipúzcoa estaban en junta general, ocupados en los medios de declarar-se en favor de la República Francesa. Un acto de arbitrariedad (sabréis a su tiempo y lugar de quién dimanó) hizo cesar las sesiones de dicha junta general. Sus miembros, que eran los que habían obtenido la confianza del pueblo por su patriotismo y probidad, fueron arrestados, conducidos a Bayona y encerrados en la ciudadela. Este acto de despotismo comenzó a agriar ii pueblo, que procuraron alejarlo más con otros excesos. La capitulación de San Sebastián fue indignamente violada; despojaron los magistrados y establecieron en lugar de ellos una comisión municipal cuyo menor defecto era la inmoralidad; cerraron las iglesias, arrestaron los clérigos, y aun las religiosas arrancadas de sus conventos fueron colocadas en unos carros y entregadas a un destacamento de húsares que, habiéndolas hecho atravesar de esta manera el país conquistado, las condujo a Bayona donde fueron encarceladas y tratadas con la mayor barbarie.

No se os puede ocultar la impresión que esta serie de injusticias, de violencias y atrocidades ha debido producir en un pueblo tan amante de sus opiniones religiosas como conocido por su respecto a la fe de los tratados. Todos los que tenían medios para huir abandonaron sus hogares y la Francia estuvo amenazada en Guipúzcoa de no haber conquistado sino desiertos así como sucedió en Cataluña.

'Ya habéis visto la conducta que se ha observado para con la Guipúzcoa. Ahora veréis cómo fue tratada la Bizcaya. Varias columnas avanzaron hasta el interior de su pais con el fierro en la mano y el fuego en la otra..... 


\section{Revista de História das Ideias}

miedo de ver comprometidas sus personas o atacada su religión, podrán volver con entera confianza y que gozarán de la libertad de sus personas, de sus propiedades y de sus opiniones conformándose con las leyes»; sinon, passé le $1 .{ }^{\text {er }}$ juillet, ils s'exposent à être considérés comme des émigrés et à voir leurs biens confisqués.

Le compte rendu de la séance de la Junta general tenue le 21 Floréal dans Saint-Sébastien occupée, a un frontispice orné de la devise: Droits de l'homme - La nation et la loi; il y est fait état du discours, acclamé aux cris de iViva la República! ¡Viva la Convención Nacional!, du représentant en mission, qui rassure l'auditoire en ces termes:

"Las bayonetas de los republicanos franceses sabrán ayudar los deseos de los republicanos guipuzcoanos para la independencia y defender su territorio de la invasión de nuestros enemigos comunes: ésta es la obligación sagrada que hago en nombre del valeroso ejército que tengo la honra de mandar";

puis du discours de Romero, diputado general de la Provincia de Guipúzcoa, qui dit:

«El pueblo guipuzcoano es digno de asociarse a la brillante suerte de la República. Ya al acercarse vuestras falanges victoriosas, había proclamado de nuevo su independencia que durante quinientos años supo defender contra las insidiosas pretensiones de un astucioso gobierno. Algunas medidas severas e impolíticas habían sofocado nuestras opiniones. Pero $i$ por qué recordar los males que nos han agobiado, cuando debemos entregarnos con efusión a la fraternidad más suave y digna de la mayor confianza? Prometemos a la República francesa que nuestras operaciones serán dictadas por nuestro reconocimiento $\mathbf{y}$ por los estímulos de nuestra libertad».

On procède aussi à la lecture du rapport de Tallien au Comité de Salut public les 3 et 6 floréal; puis on s'engage à communiquer l'ensemble de ces textes à tous les pueblos de la Province.

A cet envoi substantiel, Candamo, assez déprimé devant le tour que prennent les choses, joint également deux lettres privées avec ce commentaire:

«La una de ellas contiene tales expresiones que me animan a creer que las tres provincias vascongadas de Guipúzcoa, Viscaya y Álava, si no están enteramente contaminadas, por lo menos les falta muy poco para caer en el lazo que la primera y ponerse bajo de la protección de la Convención francesa. ¡Dios quiera que me engañe! Pero aseguro a V. Ea 


\section{L'Occupation Française des Provinces Basques}

que me temo de lo cierto porque las señales son mortales y los espíritus que las mueven tienen mucha trastienda y del mejor de ellos no hay que fiar, por ser lobos de una misma manada, sobre ser las Provincias más favorecidas de todo el reino de España. La Provincia de Alava y su Diputación a guerra reciben órdenes de la Corte, pero de la correspondencia que siguen con las dos vecinas y voluntarios alaveses tiene otros tantos correos suyos que nada mojan con los del rey, de modo que ella es la reina y dispositora de todo".

L'informateur de Godoy à Vitoria qui, de par ses fonctions dans les courriers jouit d'une position particulièrement stratégique, ne cache pas sa préoccupation et son pessimisme au vu du double jeu que mène la Province; celle-ci semble adopter une position prudente et attentiste, ne sachant comment les affaires vont tourner au cours de la campagne qui s'annonce. Quant à Godoy, il ne trouve aucun commentaire à faire, si ce n'est une nouvelle fois la recommandation de tout saisir.

Ce courrier privé, systématiquement subtilisé dans le printemps et l'été 1795 , est particulièrement intéressant, car il constitue comme un sondage d'opinion (une foi admise la réserve qu'à cette époque celui qui écrit des lettres n'est pas le tout-venant, mais qu'il appartient en quelque façon à une élite) et témoigne de l'évolution des esprits au fil des semaines. Nous en citerons quelques-unes, et d'abord les deux lettres qu'Andiazábal, de Tolosa («Pyrénées Occidentales»), envoie au «ciudadano» Francisco Lalama, à Burugarreta, le 15 et le 17 Preirial (sic) año $3 .^{\circ}$ de la República Francesa, Una e Indivisible, respectivement:

«Te remitimos esos ejemplares para que te intruyas mejor que hasta ahora, pues verás en ellos la generosidad y humanidad de los franceses para con nosotros, aunque nos hemos hallado bastante apurados no por la República francesa, sino por algunos hombres perversos que no faltan en España y en Francia....

P. D. Al amigo Arrese le incluirás los adjuntos ejemplares para que se instruya en la nueva legislación, que no se encuentran en los libros de la Recopilación».

Dans la seconde missive, sous une vignette, découpée et collée, représentant la République, on lit:

«Ciudadano... para la entrada de esta regenerada provincia o por mejor dicho la Republica cantábrica que todos apetecemos, por ser una causa muy interesante para los Guipuzcoanos.... Desengañate, Cuidadano Lama (sic), no hallarás descanso sino en el seno de nuestra regenerada patria; desasnáos, amigos míos, regresáos cuanto antes para que 
velemos a la salud de nuestra amada patria la Guipúzçoa libre. Salud, Amistad, Unión, Fraternidad.

P. D. Al fanático Arrese le entregarás las adjuntas y otras a tus amigos».

Ce Lalama, qui a quitté Tolosa et que son compatriote essaie de convaincre à la francophilie, n'est pas un inconnu pour nous; il s'agit bien du regidor Francisco Lalama qui, au début de l'année suivante, présentera une querella devant les autorités espagnoles contre un groupe de collaborateurs qualifiés; au printemps 1795, il se trouverait à Villafranca («no sé si por cobardía o por falta de algunas instrucciones», note alors son correspondant tolosan) où il fréquente Arrese (lire Carrese) le Jeune, celui qu'en 1794 Don Pablo le Père proposait à cette ville pour faire son bonheur.

Le zèle des gens des postes fait que l'on retrouve dans les liasses de l'Archivo Histórico Nacional des missives et des imprimés que l'on ne s'attendrait pas à y voir: ainsi une lettre du 24 mai 1795, adressée à José Ignacio de Benitua Iriarte, secrétaire de la Compañía de Filipinas à Madrid avec un «papelón» du Pays Basque, copie d'un journal contre-révolutionnaire, où l'on juge que les Français sont acculés. Mais le plus souvent ce sont des sympathisants de la Révolution qui se font intercepter leurs écrits: le $1 .^{\text {er }}$ juin, un certain José María écrit à sa tante: "Por Dios, tía, no hay que tener miedo: aquí y San Sebastian han vuelto muchísimos habitantes. Son humanísimos estos hombres».

On remarquera au passage que notre homme a appris sans mal le vocabulaire des conventionnels: humanos, humanidad.

Cependant que le conseiller Flores a déguerpi en direction de Santo Domingo de la Calzada et que Candamo a choisi de filer vers Miranda jusqu'à Briviesca, Dessein fait, le 15 juillet, son entrée à Vitoria. Une lettre du 16 juillet, signée d'Angela de Huicci, nous renseigne sur l'événement:

«Querida Petronila,.... Entró ayer en esta ciudad la tropa francesa en número de 4000 hombres con la mayor armonía que es ponderable, hermosa música $\mathrm{y}$ mucho orden. Clérigos, frailes y todo el pueblo estaban en las ventanas a verlos....».

Le peupe est volontiers badaud, au pays basque comme ailleurs; il ne faudrait pas en conclure à l'adhésion spontanée de Vitoria à ces conquérants. Ce que montre une autre lettre légèrement postérieure envoyée à cette même Petronila de Huicci, réfugiée à Tudela; elle est signée cette fois de son mari Mateo de Anduaga: 


\section{L'Occupation Française des Provinces Basques}

«....Viendo a los Franceses cometer los excesos que han principiado. Han mandado no se toque las campanas de las iglesias, que en las misas no se lea la oración por la felicidad de la Iglesia, del Papa y de los reyes. Han impuesto contribuciones diarias de cierto número de bueyes, vino etc. $\mathrm{y}$ últimamente toleran la violación $\mathrm{y}$ atropellamiento de mujeres.... Aquí se habla muy mal del general Crespo así por no haber admitido los grandes refuerzos que le habían ofrecido y presentado las provincias, como porque dejó escapar a 4000 enemigos que los tenía cercados en Vizcaya».

Les révolutionnaires ne se sont pas fait que des amis en Alava et ils n'ont pas été longs à froisser les populations, comme ils l'avaient fait l'année précédente en Guipuzcoa. Ce n'est peut-être pas pour l'étalage de ces abus et les sentiments francophobes qu'ils suscitent que l'administrateur des postes a arrêté cette lettre, c'est sûrement parce que, en bon basque, le correspondant tenait la balance égale entre les armées françaises dominatrices et les forces espagnoles inefficaces, soldatesque dont la conjonction représente une calamité qui dévaste la Province. Si l'on met à part une poignée de fonctionnaires aux ordres de Madrid ou une minorité de commerçants d'origine française ou d'intellectuels libéraux séduits par la Révolution, le Basque a une puissante réaction de rejet à l'égard des uns et des autres: Espagnols comme Français, les premiers se montrant incapables de le défendre contre l'exaltation des Conventionnels.

Nous ne voulons pour preuve de ces sentiments réservés que le peuple basque nourissait envers son protecteur «naturel» de Madrid, que ce rapport que José Aguirre adresse à Candamo le 17 juillet; il y évoque (vae victis!) la retraite des Espagnols filant vers l'Ouest via Mondragón, Durango, Bilbao jusqu'à entrer en Castille par Valmaseda:

«Aumentará más y más el hambre que vamos padeciendo sin comodidad, pues en todos los pueblos nos insultan con los improperios de collones y falsos, cierran las puertas de sus casas, no quieren darnos una sed de agua».

C'est le 21 juillet, et, de Miranda del Ebro, que Candamo transmet à Godoy la proclamation de 3 pages, traduite et imprimée, émanant du général Dessein, commandant les colonnes républicaines en Biscaye et Alava; elle est datée de Vitoria le 17 juillet 1795 et constitue, comme il se doit, un appel au calme et à la neutralité de la part de la population:

«....¿Por qué os separáis de vuestras mujeres e hijos?

....Cesad pues de mezclaros con nuestros enemigos, resti- 
tuiros a vuestros hogares, uniros a vuestros padres, mujeres e hijos, recoged la abundante cosecha de vuestros campos.... Las costumbres y usos son respetados; los magistrados del país ejercen sus funciones; las iglesias están abiertas; los ministros de la Iglesia tranquilos y venerados".

L'allusion à l'abondante récolte que portait la terre d'Alava n'est pas seulement un discret hymne à Cérès, lieu commun sous la plume de révolutionnaires exaltés et naturalistes, puisque des rapports aux autorités de Paris font état avec gourmandise de la bonne année que va être pour les campagnes la présente de 1795 .

Cet appel du 17 juillet contenait un point plus important puisqu'il s'achevait sur la convocation des représentants de l'Alava à la junta qui devrait se tenir à Vitoria le 20 de ce mois. De cette séance assez mémorable nous avons trouvé écho dans un rapport de Candamo à Madrid. Le 12 septembre suivant sera adressé à Godoy un exemplaire des arrêts que la Province a pris lors de ses juntes extraordinaires tenues à la suite de la proclamation du général Moncey à son entrée dans la ville, et l'attention du ministre sera alors attirée sur le cas de divers individus: Valentín de Foronda, les deux frères Urrechu et l'avocat Ezequiel de Revuelta, «quienes pretendieron trastornar el orden presumiendo que la Provincia quedaría bajo de los auspicios de la Francia». Cette déncnciation n'était qu'une confirmation car, dès le 11 août, Candamo avait écrit au Cabinet: «En Vitoria se descubrió un jacobinismo de varios sujetos con motivo de la entrega de dicha ciudad», et le 15 , ce même fonctionnaire, encore réfugié à Briviesca, avait signalé une «denuncia contra algunos sujetos de Vitoria» qui s'avérait plus explicite:

"Con ocasión de la junta particular creada en aquella ciudad después de su entrega, a que asistió el general Willot, se presentaron a ella, sin ser llamados ni representantes, Don Valentín de Foronda, Don Casimiro y Don Manuel de Urrechu, hermanos, Don Antonio Victor de la Fuente y Vargas, Don Ignacio de Acuña, Don Ignacio de Revuelta, presbítero, y varios otros, y que el primero peroró en la junta diciendo que la provincia de Álava no debía entregarse a S. M. sino es a la Convención Francesa bajo de sus auspicios y protección, respecto de haber sido vendida y desamparada en tiempo oportuno, como lo acreditaban con ciertas copias de oficios falsos que presentaron de V. Ea y de los generales que mandaban. Pero la junta prudente le respondió que aunque vieran los originales, no lo creerían por suplantados, y pidieron a Willot los hiciese salir fuera del concurso por dicha razón y no ser miembro de la citada junta, lo que se ejecutó inmediata- 
mente. Confieso a V. Ea. que el autor es algo sospechoso y no menos los sujetos que se citan y así no respondo de lo cierto pero podrá averiguarse con el tiempo....».

Candamo ne semble pas très sûr de la crédibilité de son informateur, tenu pour aussi suspect que ceux qu'il livre; cependant à son retour à Vitoria ces faits sont confirmés, comme il l'assure le 12 septembre.

Il nous reste à évoquer ce qui se passait dans la plus occidentale des provinces basques, laquelle, étant plus éloignée de la frontière française, était restée plus lcngtemps protégée de l'invasion. Nous y suivrons les tribulations de Don Juan Mariño $\left({ }^{6}\right)$, conseiller de Castille, expédié pour être l'oeil de Madrid dans le señorío, où il arrive le 18 novembre 1794. Mariño restera à Bilbao bien au-delà de la signature de la Paix de Bâle, puisqu'il y rédige encore des rappcrts à Godoy en juin 1796 . Dans l'intervalle, le 23 juillet 1795 , il avait dû plier bagages et accompagner la Diputación de Biscaye dans son reflux précipité sur Burgos. Ce sont ces semaines de juillet qui furent les plus dramatiques pour le señorío, alors même que l'on continuait à négocier à Bâle et même qu'on aboutissait, sans que rien ne fût connu sur les champs de bataille du Nord, où la ncuvelle d'une paix si désirée ne parvint pas avant le 6 août.

Jusqu'à la veille de l'occupation ennemie, les autorités bilbaínas avaient tenté de galvaniser l'ardeur des défenseurs en diffusant, le 11 juillet, une circulaire imprimée, destinée à «sostener el noble espíritu que anima a sus naturales». Cela ne fut pas suffisant. Le 14 juillet (la date n'est pas indifférente quand on sait la place de ce jour dans les célébrations révolutionnaires) est publiée une «intimación hecha por el general Moncey a los Bizcaínos». L'appel aux autorités constituées et aux habitants signé du commandant en chef de l'armée des Pyrénées Occidentales est en français et sur papier bleu pâle; il s'ouvre sur une déclaration en forme de paradoxe apparent, si l'on songe que les troupes françaises avancent en plein territoire espagnol: «Nous ne faisons la guerre que pour notre indépendance, que pour notre liberté, nous ne la faisons pas au peuple. Nous l'avons proclamé: devions-nous nous attendre queles Biscayens, connus pour leur caractère fier et peu soumis au joug de la domination, armeraient leurs bras contre les républicains français? Que leur importent nos querelles avec le gouvernement de Madrid?». Moncey distingue donc le peuple basque du «gouvernement de Madrid» en guerre avec le

(6) A.H.N. Estado 40402. 
peuple fançais. La République française «constante dans ses principes, respectera votre territoire, vos usages, vos coutumes». C'est une promesse donc de non-annexion et de sauvegarde des fueros, qui n'est pas superflue après les agissements de l'occupant durant l'année précedent en Guipuzcoa, où précisément c'est l'annexion pure et simple, agrémentée de persécutions religieuses, qui est à l'ordre du jour. Les Biscayens, qui observeront une stricte neutralité, devront envoyer sous 10 jours à Vergara, en Guipuzcoa, des députés représentant la Province.

Le 19 juillet les Français entrent à Bilbao. Dans le texte de la capitulation, la Biscaye a exigé 5 points: conserver la religion; ne pas avoir à prendre les armes contre l'Espagne; ne pas laisser toucher à ses intérêts; respecter ses fueros, privilegios, buenos usos, costumbres, exenciones y libertades; conserver ses terres et ses biens. Remarquons au passage l'accumulation des mots désignant les droits particuliers et franchises de ce pays, ce qui prouve, s'il en était besoin, l'attachement des Basques à leurs fueros.

Le 23 juillet un rapport pessimiste de Mariño fait le point pour Godoy. Installés depuis quelques jours à peine dans la ville, les occupants «emplean en Bilbao todos los medios de halago y urbanidad para concluir la obra de seducción que han empezado, con cuyo artificioso sistema temo destruyan en mucha parte le energía de Biscaya y de los pueblos fronterizos». Il s'agit des villages et bourgs à l'est de la Province, aux confins du Guipúzcoa. L'envoyé de Madrid fait part du découragement des Biscayens, c'est-à-dire de leur résignation à collaborer. De fait, on peut penser avec lui que le señorío (ou du moins ses élites) va basculer, comme l'avait fait une bonne partie du Guipúzcoa au cours de l'année précédente.

«La Diputación de Biscaya afligida en Burgos» informe le Gouvernement central que la Junta de Guernica, soit les Etats-Généraux du señorio, «ha dado las gracias a la ciudad, villas y anteiglesias por el obsequio que hicieron al general enemigo en su tránsito»; pour les fidèles au Cabinet de Madrid, à présent repliés en Castille, leurs compatriotes ont bien perdu leur caractère "firme y nervioso» et la Diputación conclut: «No es creíble que la astucia venenosa de los Franceses pudiese variar sus honrados principios en tan corto tiempo».

Lors de l'exode de juillet, au moment du sauve-qui-peut qui jette certains Basques sur les routes, un incident éclate dans le village montagnard d'Orduña, situé aux portes de la Castille et alors siège des douanes. Mariño racontera le 24 octobre suivant: 


\begin{abstract}
"Algunos vecinos de la ínfima extracción no permitieron con las armas en la mano que los caballeros sacasen sus muebles y caudales ni aún los del administrador de la aduana ni los respectivos papeles de su oficina, bajo el pretexto de que extraían trigo a pesar de haber reconocido por sí mismos que los carros no llevaban más que fanega y media de harina para el consumo de la familia de los amos, faltando al respeto al alcalde y profiriendo la expresión de que ya eran todos iguales y se debían repartir los bienes de los ricosn.
\end{abstract}

Ces paysans montrent qu'ils ont vite appris et bien retenu la leçon d'égalité donnée naguère par la Révolution et que bien plus ils s'avèrent d'horribles "partageux», dont la réaction de classe relève de l'esprit jacobin le plus enragé. Tout ceci sur fond de pénurie frumentaire, comme le rappele Vilar ( $\left.{ }^{7}\right)$ : dès 1793 une crise de «type ancien» s'est abattue sur le pays; le prix du blé monte de façon brutale, si bien qu'en 1794 la résistance populaire est vive dans les bourgs à l'ouest de SaintSébastien contre les Français pilleurs de magasins de farines. Vilar souligne le caractère conjoncturel d'une rébellion paysanne qui se serait aussi bien dressée contre les autorités du pays, s'il n'y avait eu l'invasion pour la catalyser sur les Français. A Orduña, au début de l'été suivant, précisément la veille de l'arrivée des ennemis, si les villageois s'en prennent sans ménagements aux nantis qui fuient devant l'avancée républicaine, c'est pour les empêcher de vider l'endroit de ses réserves, ce que Mariño, dont on peut suspecter l'objectivité, traduit par «bajo el pretexto de que extraían trigo»; c'est son interprétation, mais ce qui pour un conseiller de Castille n'est qu'un prétexte, représente pour le populaire basque une raison des plus sérieuses.

Godoy ne renonce pas pour autant à continuer, à l'intention des sujets du roi d'Espagne, un intense travail psychologique, allumant des contre-feux, inspirant la contre-propagande face aux menées des Conventionnels; le 27 juillet, au vu des nouvelles alarmistes de Bilbao, il décide d'insérer dans la Gaceta de Madrid un article anonyme révélant la conduite des Français: à leur entrée dans la ville, ils ont exigé sans paiement 4000 paires de chaussures et autant d'espadrilles; pour leurs chevaux ils font faucher le blé encore sur pied dans les champs. "Todas las funciones son propias de una conquista hecha a fuerza viva», conclut le bulletin. Le 29, Mariño accuse réception de la consigne que l'on vient de lui donner

(7) P. Vilar, Hidalgos, amotinados y guerrilleros, Barcelona, Crítica, 1982, pp. 185-186. 
depuis Madrid: «que por conductos secretos haga circular las ideas oportunas a fin de sostener la lealtad y amor a S.M.». $\mathrm{La}$ guerre psychologique bat son plein.

2. L'évacuation des troupes républicaines et la répression au Pays basque après la paix de Bâle

$\mathrm{Au}$ début du mois d'août, un revirement brutal s'opère dans les Provinces basques lorsque l'on apprend que les Français vont quitter le pays. Parmi les lettres qu'avec un zèle particulier Candamo a saisies, figure celle, touchante, que le 1. ${ }^{\text {er }}$ septembre (15 fructidor An III) Payrard écrit en français de Tolosa, à Ramón de Zubia, résidant à Vitoria. Les Français vont évacuer; aussi lui réclame-t-il pour son père 4 onces de «chou fleuri»; il joint à sa demande quelques journaux français dont les Espagnols étaient si friands: «malgré qu'ils ne soient pas bien intéressants, je pense que vous les verrez avec plaisir»; il compte bien qu'il les fera passer aux amis. Il s'agit de $5 \mathrm{nu}-$ méros (53 à 57 ) de La sentinelle par J. B. Louvet (du Loiret) représentant du peuple. Candamo assortit son envoi d'un avis sur la conduite du destinataire Zubia: «hijo de ésta (Vitoria) sujeto bastante afrancesado». Ce dernier mot qui fera florès durant la guerre d'Indépendance a déjà cours.

Le 5 septembre, Candamo ajoute cette précision:

«Los famosos Romero y Aldamar han dirigido los días atrás circulares por todos los pueblos de Guipúzcoa convocándolos a juntas generales para Cestona, pero Don Miguel de Mendinueta, noticioso del pasaje, ha frustrado el empeño de ellos haciendo ver que la Diputación legítima de Guipúzcoa es la nombrada en Mondragón el año pasado».

Nous voyons comment les députés collaborateurs ne se sont pas avoués tout de suite battus et comment le légat du Conseil de Castille réapparaît à point nommé après son éclipse pour faire entendre, en ces semaines de grande confusion, la voix de Madrid.

A Vitoria, le 6 octobre, Candamo en est toujours à arrêter le courrier de France: voilà que de Bayonne est arrivée une lettre qu'il transmet à Godoy; elle vient du «célebre Faronda (sic) que se fue de aquí con motivo de la peroración que hizo en las juntas que tuvo la Provincia de Alava cuando estaba de comandante de las tropas francesas $\mathrm{Mr}$ Billot». La lettre autographe de Foronda, qui semble s'être réfugié à Bordeaux, est laconique; elle est adressée, le 5 octobre 1795, à Martín 
Antonio Huici, Directeur de la Compagnie des Philippines à Madrid, avec un lot de Moniteurs. Candamo n'aura pas longtemps le plaisir d'intercepter les journaux envoyés de France; le 28 novembre il accuse réception à une circulaire de Godoy datée du 20, le priant de laisser passer les divers papiers nouvelles en provenance du pays voisin et adressés à des particuliers. Les relations se normalisent donc entre la République française et sa nouvelle alliée.

Cependant la répression s'était mise en branle contre les afrancesados notoires et scandaleux; un procès fut fait à ces Français et francophiles de Tolosa dénoncés par Lalama (dont on peut se demander, au vu de certaines lettres à lui adressées si lui-même fut toujours blanc comme neige). Le regidor de Tolosa et le syndic procureur général Mateo de Larrea terminaient leur plainte en soulignant à plaisir la particularité basque, mais c'est pour dire que, plus que toute autre, la Province est fidèle au roi d'Espagne, et si les fueros y sont mentionnés, c'est dans l'expression «nuestras leyes del reino y fueros» (l'un corrigeant l'autre) et pour rappeler à quel point tous ces vénérables monuments ont été intraitables envers les traitres:

«En todos los gobiernos y provincias se debe tratar con mucho rigor a los traidores y en todos se les debiera considerar por hombres de distinta especie e insociables; pero en nuestra Provincia conviene ser mayor la aversión hacia ellos, ya porque en todos tiempos ha sido ejemplo de fidelidad $\mathrm{v}$ amor a sus reves, ya porque profesa indecible odio a sus desleales y traidores y ya porque se complace en ver destruidos a todos éstos, vengada la majestad y airosa su reputación".

Le conseiller Flores Manzano ne fait plus, autant que nous sachions, parler de lui après l'hiver 1795; il en va différemment de Mariño qui, à Bilbao, reprend les choses en mains après le départ des Français.

Certains notables francophiles seront, en raison de leur qualité, traités avec humanité, d'autant que les républicains français, qui ont fini la campagne en beauté, ont pu imposer leurs conditions et exigé le pardon des collaborateurs. La plupart des afrancesados sont grâciés, tandis que ceux qui s'en prirent aux Espagnols, et surtout à leurs richesses, sont condamnés. Quand Mariño réintègre la Biscaye, il ne se fait pas faute d'entamer contre les villageois d'Orduña un procès, aux termes duquel tous les accusés se retrouvent condamnés aux travaux forcés (trabajos de las obras de la plaza de Pancorbo); Josef Paul, le meneur (car il en faut un), pour une durée de 


\section{Revista de Historia das Ideias}

6 ans, ses 12 compagnons pour 4 ans. Et le représentant du premier corps de l'Etat, le conseiller de Castille Mariño, de conclure avec satisfaction: «Es el único crimen en Biscaya y por unos hombres rústicos, vinosos y de mala educación». Ils paieront leur mauvaise éducation en gachant le mortier pour édifier la forteresse de Santa Engracia, sans que le Directoire, volontiers sensible aux malheureuses victimes de la répression, ne songe à lever le petit doigt pour eux.

Un procès fut intenté par les autorités civiles aux commerçants français de Tolosa, ainsi qu'à leurs amis de la région, qui étaient compromis avec l'occupant; l'âme de la trahison, il fallait la chercher dans le clan Carrese d'origine béarnaise (père, fils et gendre), qui aux sympathies idéologiques patentes avec la Révolution alliait un grand sens des affaires. si bien que, la guerre finie, la République lui devait 880369 livres au titre de fournitures aux armées ( $\left.{ }^{8}\right)$. Nous avons retrouvé un dossier inquisitorial ouvert en 1790 au nom de Juan Antonio Carrese. marchand à Tolosa por cause de "propositions» ( $\left.{ }^{(}\right)$; il tenait des propos libertins, assurant que, l'homme étant libre, cn ne saurait lui prohiber de commettre le péché de luxure, et lirait des livres interdits, notamment le Contrat social de Rousseau. L'accusé avait épousé une Francaise et partit en France en compagnie de son frère José María lors de la paix de Bâle: en 1800 il est consul d'Espagne à Paris, et donc hors des atteintes de l'Inquisition. On apprend que si alors Juan Antonio n'a rien eu, il ne va différemment pour les autres: au terme du procès politiaue (causa por infidencia y deslealtad contra el soberano) aui leur est intenté, tous. sauf le père Carrese. se voient infliger par le conseil de guerre siégeant à Pampelune à la fin du siècle une peine d'exil aux Philippines pour une durée de dix ans; cependant on nous précise qu'ils cnt été bien vite aministiés par Charles IV.

On trouve ailleurs mention du procès de Pampelune de 1799 où un tribunal militaire condamna un certain nombre de notables basques dont Domingo Adrian de Aguirre (encore un Tolosan, mais dont nous ignorons s'il est le gendre de Carrese, Adrian de Aguirre), un fuerista de Guipúzcoa qui

(8) Sur Carrese, on verra Sebastian Insausti, «Apuntes para una historia comercial donostiarra. Un clan de comerciantes zuberotarras: Pablo Carrese Barrullet», Boletín de estudios históricos, San Sebastián, n. 4 , 1970, pp. 273-288. Sur ce personnage ainsi que sur certains autres (Echave Romero, Aguirre, Barroeta) j'ai consulté la Enciclopedia general ilustrada del Pais Basco, Auñamendi (en cours de publication).

(9) A.H.N. Inquisición 3731-51. 
participa à la Junta collaboratrice de Guetaria; après une condamnation sévère pour la forme, l'amnistie du roi ne se fit pas attendre.

Un certain nombre de ces afrancesados choisit la fuite en France; parmi eux figure également Joaquín Barroeta, qui s'exile à Paris, d'où il adresse en avril 1797 un placet à Godoy, et qui, ayant reçu le pardon du roi, rentrera au pays pour à nouveau servir Joseph Bonaparte après 1808.

Si l'autorité civile ne se fit pas faute de traîner devant ses tribunaux les individus qu'elle jugea trop ostensiblement compromis, elle fut largement secondée avec un zèle qui ne se démentit jamais par le Saint Office de l'Inquisition, lequel était depuis l'automne 1789 au service du gouvernement. Dans le pays basque il se distingua par un labeur infatigable contre tout ce qui venait de l'étranger et surtout de France et pouvait véhiculer les idées nouvelles, sans faire jamais le distinguo entre les Basques de souche et les gens venus du reste du royaume: aussi relève-t-on dans ces fichiers à côté d'innombrables patronymes basques, les noms d'hommes aussi différents que José Antonio Enriquez $\left({ }^{10}\right)$, commissaire de la marine et juge de la contrebande à Saint-Sébastien, inquiété pour mauvaises lectures, bien qu'il dise avoir coopéré avec l'Inquisition pour filtrer l'entrée des livres étrangers et que, à trop vouloir empêcher la contrebande, il se soit fait la bête noire du commerce basque; ou qu'Antonio Ricardos, qui avait été capitaine général à Saint-Sébastien et est poursuivi le 18 novembre 1793 pour "proposiciones adictas a las actueles turbulencias de Francia» $\left.{ }^{11}\right)$. Les temps étaient si difficiles dans les années de la Révolution que le Saint-Office dut, après la tourmente, faire le ménage jusque dans ses rangs: le 3 avril 1797 une «sumaria» est communiquée à la Suprema contre Fernando Garaioa, notaire du saint tribunal à Saint-Sébastien $\left({ }^{12}\right)$ : le familier Manuel de Iturralde le dénonce pour "propositions et adhésion à la République française». Un prêtre Diego Lazcano déjà suspect avant la Révolution (il est dénoncé dès 1787 alors qu'il était bénéficier à Tolosa) a beaucoup à se reprocher selon les inquisiteurs; il est dit prêtre sécularisé et

(10) A.H.N. Inquisición 3732-86.

(11) A.H.N. Inquisición 22432 2. Ricardos meurt pendant la première année de la guerre (un peu plus tard l'Inquisition inquiétera pour lecture de livres prohibés un marin qui devait s'illustrer à Trafalgar, Cosme Churruca). Ne pouvant plus s'en prendre au général Ricardós, elle poursuit son secrétaire José Bosque qui serait en possession de livres défendys et aurait adopté les mêmes maximes que son patron.

(12) A.H.N. Inquisición 2244. 
semble s'être marié; en tout cas, il a fui en France, où il publie, à Bayonne, en 1797, Satisfacción de los cargos que se le hacen sobre la conducta que ha tenido mientras las tropas francesas ocuparon el Reino de Navarra y Provincia de Guipúzcoa. Le Saint-Office fait qualifier l'ouvrage où l'on trouve à épingler des «propositions hérétiques, téméraires, injurieuses envers les Sacrés Conciles et les Souverains Pontifes» $\left({ }^{13}\right)$.

José Hilarión de Maíz, notaire à Beasain, avait fait partie de la Junta de Guetaria; aussi il n'y a pas lieu de s'étonner de le voir fiché, le 26 mai 1795, pour «propositions». Contre lui on prétend que lorsque les Français sont venus, il n'a plus suivi les préceptes de la religion et s'est abstenu de faire ses Pâques; c'est un mécréant qui dit pis que pendre des moines, critique la dîme, assure du roi qu'il est un «cabrón» et de la reine une «puta», bref il est pour la France. On lui entend dire que la liberté des Français est meilleure que notre religion. "Mirad, mirad vuestras ilusiones, disait-il à mesure que les soldats ennemis avançaient, ¿qué hacen ahora los santos que no hacen milagros?» Quand le panorama intérieur eut changé avec le départ de l'occupant, Maíz retomba prestement sur ses pieds, il fit son autocritique («espontánea»). En effet, a l'instigation de Godoy, l'Inquisition envoya une circulaire aux gouverneurs du diocèse de Pampelune «invitando a todos aquellos que, mediante la estancia de los Franceses en aquella Provincia, hubiesen incurrido en aún desliz o persuadidos ser de alguna falsa doctrina a que se espontaneasen y hagan verdadera confesión de todas las faltas en que creen haber incurrido». On interrogea le notaire, on voulut savoir s'il avait tcujours la Proclama hecha por el pueblo francés de los derechos del hombre; il assure les avoir brûlés, il n'a rien d'autre et ignore si quelqu'un possède ce type d'écrits, et pour attendrir les inquisiteurs il rappelle qu'il a été emmené à Bayonne par les Français avec d'autres membres de la Junta de Guetaria et qu'à son retour il est resté à Saint-Sébastien. Il fut absous comme la plupart de ses pareils; du moins on classa l'affaire $\left(^{14}\right)$.

Pour Foronda - comme pour les autres exilés politiques -, les choses s'arrangent également assez vite, puisque dès 1799 on le retrouve en train d'écrire à son compatriote le ministre Mariano José de Urquijo pour s'offrir à rédiger une publication périodique intitulée d'un mot qui sent sa Révolution: La Humanidad $\left({ }^{15}\right)$. Non sans qu'auparavant il n'ait

(13) A.H.N. Inquisición 3732-181 et 4481-9.

(14) A.H.N. Inquisición 3732-96.

(15) A.H.N. Estado 3238-16. 
été lui aussi l'objet de la sollicitude du Saint-Office qui lui intente un procès, en même temps qu'au marquis de Narros, dont le destin était depuis plusieurs années uni au sien: d'abord à Vergara, au sein du fameux Séminaire créé par la Société des Amis du Pays, puis à Vitoria, quand l'invasion française eut interrompu la carrière brillante de cet établissement. Procès «sobre la influencia que tuvieron en la ocupación de Guipúzcoa por los Franceses >, dont il ne sortit rien, comme c'était souvent le cas dans les derniers temps de l'existence de l'Inquisition, et plus encore lorsqu'il s'agissait de procès politiques à peine camouflés en procès de foi et que le personnage visé n'était rien moins que l'illustre marquis de Narros $\left({ }^{16}\right)$.

Les cas cités ci-dessus représentent simplement quelques exemples de collaborateurs réels ou supposés, civils et ecclésiastiques, basques et basquisants ou représentants du pouvoir central, exilés ou repentants, traînés devant la justice militaire ou devant le tribunal de la foi. Nous n'avons pas eu en mains de document nouveau récapitulant toutes les affaires d'afrancesamiento jugées après la Paix de Bâle. Pour le seul tribunal de l'Inquisition nous avons trouvé, dressé par son tribunal de Logroño pour les trois Provinces, l'état des causes classées ou du moins suspendues de 1789 à 1794 et des causes en cours en 1795; nous en avons extrait les cas qui, de près ou de loin, concernent la France (et qui sont les plus nombreux): sympathies révolutionnaires, accusés français ou d'origine française, voire émigrés français; on trouvera cet état publié en appendice; il pourrait être complété par le Catálogo de alegaciones fiscales conservées à l'Archivo Histórico Nacional, publié en 1977 par Natividad Moreno. L'impression que l'on retire à manier ces documents, c'est que l'impact de la Révolution française fut bien réel au Pays Basque, et même au-delà, bien que nous n'ayons pas à en parler ici. On s'est plu à souligner que la Convention montagnarde avait par une politique brutale gaché ses chances d'établir au Guipúzcoa un régime allié, comme cela se fera en Europe avec la fondation des républiques-soeurs; le peuple s'y dressa contre ses soldats et seule collabora une minorité de négociants, bourgeois acquis à un

(16) Dans son périple au Pays Basque en 1797, Jovellanos rencontra le vieux marquis «amable, ardiente, algo precipitado en su habla, de fogosa imaginación, entusiasta por los Franceses». Il avait été dénoncé quelque temps plus tôt pour ses sympathies révolutionnaires: «Hasta las viejas de Vitoria se explicaban sin reserva contra el marqués diciendo: 'este hombre ha perdido a la Provincia de Guipúzcoa'»; quant à Foronda, on le dit «afecto a las máximas de Francia por lo que hace a independencia y libertad" (A.H.N. Inquisición 3732-179). 
certain libéralisme économique, ou de juristes héritiers naturels des Lumières; une élite bourgeoise donc, ce qui n'est pas déjà si mal, et qui pèse dans la vie de la Province d'un poids plus réel que son nombre pourrait le faire croire; de plus, tant qu'on n'aura pas évalué au plus juste cette première vague d'afrancesamientos malheureux, d'émigration politique d'inspiration libérale, qui toujours (sentiment de culpabilité tenace oblige) a été gommée par l'historiographie espagnole, basque et même française, on ne sera pas en mesure de tirer des conclusions valables sur cet épisode de 1795 , bref mais comme prémonitoire de la guerre d'Indépendance.

En 1796, tout semblait devoir rentrer dans l'ordre. Il n'empêche que, mal remis d'un traumatisme récent, le gouvernement de Madrid désire, le 31 mai, en savoir plus «acerca de la celebración de la Junta general ordinaria que bianualmente suele celebrar só el árbol de Guernica ese señorío». Godoy exige donc «la más exacta pesquisa sobre lo que ocurra ahí, pues tiene entendido de que el humor republicano se conserva y concentra en el país». La consigne qu'il passe à son émissaire est la suivante: «avisar de todo cuanto note, pues si el tiempo pasa sin precaver resultas, llegará la desgracia al extremo de conocer por enemigos a esos naturales».

Le 18 juin Mariño signe un rapport assez rassurant: la junta s'est bien tenue pour voter les frais de guerre, elle n'a siégé que 7 jours, ce qui est peu; de plus il n'y a rien à signaler:

"Pero es cierto, ajoute-t-il, que los Biscaínos son muy adictos a su constitución contradictoria y mixta de monarquía y democracia, porque son libres en comprar y vender, nada contribuyen, no admiten tropa no siendo de tránsito, y gozan de una igualdad absoluta, acaso mayor que la de los Griegos y Romanos en las épocas pasajeras de gobierno popular, bien que al mismo tiempo reconocen dichosamente a S.M. por soberano en calidad de señor que nombra al corregidor teniente de Guernica para que les administren justicia, al paso que ellos eligen diputados generales del señorío que son jueces de apelación de las providencias de aquéllos, y todos están sujetos al mayor de Bizcaya, sala de oidores de Valladolid y Consejo de Castilla. Aunque los naturales del señorío aman mucho a su patria con exclusión de las demás provincias de España, siempre he observado un profundo respeto hacia la persona de S.M. Sin embargo es menester confesar que en todas las provincias libres hay cierto espíritu de orgullo poco conforme a la obediencia y subordinación de las otras (lo que me mortificó no pocas veces); pero a pesar de esto siempre he advertido una aversión nada afectada al sistema de los Republicanos franceses, a cuya nación aborrecen muy de veras, sea por rivalidad de vecinos o porque todos o los más de los que 
se establecieron aquí se hicieron ricos por su mayor inteligencia o fortuna en el comercio».

A défaut de sentiments enthousiastes, ou du moins positifs, c'est la méfiance que le voisin français a fait naître en plusieurs siècles de rivalités, et surtout la haine que l'occupant français a su susciter en quelques mois qui, selon Mariño, servent de garant de la fidélité monarchique des Basques. L'envoyé de Madrid se doit de confesser qu'à cause du tempérament basque et du statut de ce pays, il a dû à ce jour avaler force couleuvres.

\section{Conclusion}

La conquête des provinces espagnoles du Nord par les armées de la Convention est'restée, deux siècles après les événements, plus plongée dans l'ombre que tout autre épisode des guerres de la République ou que les événements de la guerre d'Indépendance; c'est la raison pour laquelle, en attendant la grande publication promise par Antonio Elorza, il ne nous a pas semblé inutile de présenter et de commenter des documents qui font état de l'opinion dans les trois Provinces à cette époque. A voir de récentes biographies de ces hommes (tel Foronda) impliqués dans l'occupation de leur pays, faire impasse (ignorance ou offuscation, qu'importe!) sur certaines tribulations de ces libéraux, nous avons cru devoir indiquer que, dès 1795 , le Sud-Ouest de la France avait servi un temps de terre d'asile pour ceux qui, peut-être moins au nom des fueros que de l'idéologie révolutionnaire, moins au nom des libertés du Pays basque que de la Liberté française, étaient en délicatesse avec Madrid, initiant une tradition de «sanctuaire» qui s'est maintenue bien vivante jusqu'à nos jours. 


\section{APPENDICE}

\section{REVOLUTION, PAYS BASQUE, INQUISITION}

I - Sujetos testificados y procesados en este Santo Oficio de Logroño de los pueblos de las tres Provincias de Vizcaya, Alava y Guipúzcoa, cuyas causas se hallan suspendidas.

* 1789

Bilbao obscena.

Carlos Lecur, por proposiciones contra la fe y tener una pintura Marquina

Fr. Francisco Errasti, religioso agustino calzado, por apoyar las máximas francesas.

* 1790

Vergara

Don Carlos Droville, de nación Francés, por proposiciones contra la fe, acumulada a otra causa que por los mismos delitos se le hizo en el año de 1789.

Vitoria

Don Trifón de Echeverría, teniente del alcalde de Vitoria, por tener y leer los discursos y papeles de la Asamblea de Francia prohibidos.

* 1791

Bilbao

Julián el Barquero, por hablar en defensa de la Francia

Mr. Bandillon, presbítero francés, por haber jurado sin restrición a la Asamblea.

Don Ignacio Landaburu, por adhesión a la Asamblea Francesa

Juan Cadet, francés, por proposiciones contra la fe en favor de la Asamblea Francesa.

Don Pedro Sansarrie, Francés, por proposiciones contra la fe

San Sebastián

Don Antonio Tastet, comerciante, por proposiciones contra la fe.

Don Marcos Barangot, por proposiciones contra la fe, y adhesión al sistema y libertad de Francia.

* 1792

Azpeitia

Antonio y Guillermo Forni, Juan Amban y otros sus socios, caldereros franceses, establecidos en la villa de Azpeitia, por máximas y proposiciones seductivas a insurrección.

Oñate

Don Josef de Landa, catedrático de filosofía en Oñate, por aprobar el sistema y máximas francesas, sobre que fue 'prevenido reservadamente por el comisario de Oñate, de orden de S.A. de 5 de abril de 1793.

Bilbao

Esteban Andrés y Beltrán, de nación francés, por expresiones en favor de la Asamblea Francesa.

Juan Sartu, francés, por proposiciones inductivas a insurrección contra las supremas potestades, de lo que fue reprehendido a presencia del alcalde de la villa de Bilbao por el comisario de orden de S.A., 8 de enero de 1793. 


\section{L'Occupation Française des Provinces Basques}

Mr Bousigues, presbítero francés, cura de Castres, por haber prestado el juramento constitucional.

* 1793

Sollo

Lon Juan Antonio de Jugo, cural del Sollo, por proposiciones contra la fe y manitestar inclinación al gobierno trancés.

Vitoria

Mr Jean Mothe, Francés, por conspirar a la insurrección de los Españoles contra las supremas potestades, mandado salir de España por decreto de S.A. de 21 de marzo de 1793.

San Sebastián

Mr Bretuz, Francés, por proposiciones contra la fe contra la fe.

Don Bernardo Dehez, comerciante francés, por proposiciones Bilbao

Don Joseph Des Esart, presbítero, por retener libros prohibidos. y Francia.

Don Juan Sitre, Francés, por hablar contra los reyes de España

Pedro Lagarra, por proferir expressiones en favor de la Asamblea; reprehendido y conminado.

Don Bonifacio de Amezgaray, alférez de navío, por aprobar la muerte del rey de Francia y la conducta de la Asamblea.

Don Domingo de Lesca, Don Arnoldo de Surisarry, Don Pascual de Ardanas, Don Nicolas de Guendica, Don Manuel Sancho Corredor, Don Luis Des Esart, Don Pedro Ardanas, Don Juan Lafon, Don Luis Riolet, Don Manuel de Bergareche, un hijo de Don Germán de Loransin, por afectos a la $\Lambda$ samblea de Francia, verter proposiciones en su defensa, y muy injuriosos contra los soberanos, reprehendidos.

Don Raimundo Dubal, presbítero francés, por proposiciones contra la fe.

Don José Mallagara, presbítero, antes religioso del Carmen descalzo y en la actualidad cura intruso en Francia, por haber incurrido en el cisma y demás delitos que abundan en el día en aquel reino.

Pedro Daguerre, Francés, por adicto a las máximas de la Asamblea, está encargado el comisario de observar sus operaciones. tra la fe.

Don Pedro Foyada, presbítero francés, por una proposición conFrancia.

Mr Lafon, modista francés, por hablar de las ventajas de la

Don Salvador de la Azuela, por expresiones contra los sacerdotes franceses, adhesión sobrada al libertinaje y demasiada facilidad de tratar de desórdenes carnales; reprehendido por el comisario ante un notario del Santo Oficio.

* 1794

Lanciego Francia.

Francisco Naya, por proposiciones a favor de las máximas de la

Bernedo

Bernardo Ramón Pages, guarda del tabaco, por proposiciones contra el Estado y las de aprobar la muerte del rey de Francia, y decir que importaría poco hiciesen lo propio con el de España.

Bilbao

Don Lorenzo Fransine, comerciante francés, por inobservante de los preceptos eclesiásticos. 


\section{Revista de História das Ideias}

Don Juan de Equillotat, presbítero francés, por tener una medalla alusiva a las turouiencias de la Francia y resistirse a entregarla, sobre cuyo asunto el comisarıo Don Joaquin de Ampiero, que 10 es de aquel puerto represento al Señor Inquisicor general, y se esperan las resultas. de Francia.

Jose de Cortesana, por expresiones de adhesıon a las máxımas

San Sebastián

Fr Juan Bautista Altuna, guardián que era del convento de San Francisco de San Sebastián, y al presente internado en la Francia, por solicitante.

Don Josef de Cives, comerciante en Santander, en la actualidad residente en Santander, por proposiciones heréticas y otras sediciosas y subversivas de la potestad suprema del soberano.

Don Enrique Mallar, comandante que fue de Bayona de Francia, por proposiciones contra la fe e Inquisición, reprehendido con aprobación de S.A.

II - Sujetos testificados y procesados en reste Santo Oficio de la Inquisición de Logroño de los pueblos de las tres Provincias de Vizcaya, Alava y Guipúzcoa, cuyas causas se hallan pendientes en 1795.

Amurrio

Don Vicente Anastasio Lample, abogado de los Reales Consejos, por proposiciones contra la fe, inobservancia de los preceptos eclesiásticos y publicar no deberse llevar dinero por las bulas, aprobando en esta parte el sistema francés.

Bilbao

Carlos Delmás o Delmace, Francés, que anda de feria en feria, por proposiciones contra la fe.

Francisco Popar, Francés, por proposiciones heréticas y por afirmar que el hombre no debe obediencia al papa, rey ni superior alguno (hizo fuga).

Don Juan Jobins, de Nación Francés, por proposiciones contra la fe $\mathrm{y}$ retener libros prohibidos.

Don Juan Pedro Lapose, presbítero francés, por haber sido fracmasón.

Jyan Franco, Francés, por desprecio de las indulgencias, de los ministros de la penitencia, del Santo Rosario.

Don Juan Labergne, estudiante francés, emigrado que al presente reside en Madrid, sobre tener libros prohibidos, y sospechoso de haber propalado existir en dicha Corte muchos patriotas franceses y opinar no haber inconveniente en prestar el juramento de la nueva constitución.

Don Lorenzo Fransine, Francés, comerciante, por no oir misa los días festivos.

Don Pedro Dihave, capitán francés, por proposiciones en defensa de las revoluciones de la Francia, contra la potestad pontificia y contra el Estado.

Vergara

Francisco Chamaneaux (sic), maestro de quimia en el Seminario de Vergara, por decir proposiciones contra la fe, y sospechas de haberlas enseñado heréticas.

Don Valentín Foronda, por protector de las máximas francesas $\mathrm{y}$ apasionado a su gobierno.

Don Joaquín de Eguía, Marqués de Narros, por protector de las máximas francesas y apasionado a su gobierno; además de esta causa 
se remitieron a S.A. en 27 de agosto de 1790 once piezas de otra seguida en este Santo Oficio contra el dicho Marqués de Narros, con las diligencias, practicadas de orden de los Señores del Consejo a consecuencıa de la orden de 21 de mayo de 1789.

Legorreta

Pedro Juan de Odriozola, cirujano en el lugar de Legorreta, por proposiciones y mala doctrina; está mandado poner en cárceles secretas con aprobación de S.A., lo que no se ha ejecutado por hallarse el reo en el territorio ocupado por los Franceses.

Tolosa

Don Antonio Carrese, por proposiciones contra la fe y retener libros prohibidos, no oir misa en día de precepto, comer carne en los prohibidos, no confesar voluntariamente y por tener alguna pintura obscena.

Don Juan Pablo Carrese, por proposiciones contra la fe y gobierno.

Don Felix Montes, sacerdote francés, por proposiciones y adhesión o inclinación al sistema republicano de Francia.

Vitoria

Eugenio de Villodas, sirviente del patrón de Murua, por proposiciones contra la fe y hablar al parecer en favor de la Asamblea Francesa.

Don José Segurola, asesor del diputado, y don Antonio Vargas, abogados de la ciudad de Vitoria, Don N. Emparan, protectores de las máximas francesas, como apasionados a su gobierno, y el hijo de la patrona de Murua.

Don José Hortiz, capitán del Regimiento de las Ordenes, que al presente se halla en Mondragón, por tener un papel en que se proponen las máximas de la Convención francesa y se procuran persuadir con toda eficacia.

Nicolas Budet. Francés, por proposiciones y burlarse de la procesión al Santisimo Rosario.

Sebastián de Gamboa, por proposiciones contra la fe y adhesión a las actuales providencias de la Asamblea Francesa.

(Archivo Histórico Nacional-Inquisición 2243-2). 